\title{
A CRISE COMO OPORTUNIDADE PARA O EMPREENDEDOR BRASILEIRO
}

Prof. Dr. Marcelo T. Okano

Marcelo.okano@cps.sp.gov.br

Professor do Mestrado Profissional em Gestão e Tecnologia em Sistemas Produtivos

Doutor em Engenharia de Produção

Doutorando em Administração na FGV/EAESP

Prof. Dr. Marcelo Eloy Fernandes

marceloeloyfernandes@gmail.com

\section{Resumo}

O empreendedorismo é um marco na estrada para o progresso econômico, e faz uma contribuição enorme à qualidade e às esperanças futuras de um setor, de uma economia ou mesmo de um país. O objetivo deste artigo é comprovar que nos momentos de instabilidade econômica aumenta-se o numero de empreendedores através de dados de pesquisas de instituições reconhecidas utilizando fontes de evidencias quantitativas. Este estudo trata-se de uma pesquisa exploratória, baseada em dados secundários, com análise quantitativa de dados e amparada na literatura científica. Enquanto os indicadores econômicos apresentaram índices negativos devido a uma crise econômica, os indicadores de empreendedorismo mostraram uma reação inversa com índices positivos, caracterizando um aumento nos empreendimentos.

Palavras-chaves: Empreendedorismo, Crise, Desemprego 


\begin{abstract}
Entrepreneurship is a milestone on the road to economic progress, and makes an enormous contribution to the quality and future hopes of a sector, an economy or even a country. The objective of this article is to prove that the moments of economic instability increase the number of enterprises through data from surveys of institutions recognized by sources of quantitative evidence. This study is an exploratory research, based on secondary data, with quantitative data analysis and supported by the scientific literature. While the economic indicators presented negative indexes due to an economic crisis, the indicators of entrepreneurship showed an inverse reaction with positive indexes, characterizing an increase of the enterprises.
\end{abstract}

Keywords: Entrepreneurship, Crisis, Unemployment

\title{
1. Introdução
}

O desemprego aumentou nos últimos anos, segundo os Indicadores do IBGE (2016), em junho de 2015 tínhamos 8,354 milhões de desempregados e em junho de 2016 aumentou para 11,586 milhões. Boa parte da perda de empregos deve-se a crise econômica em que o Brasil está passando.

De acordo com Singer (2008), o surgimento do desemprego em escala crescente na maioria dos países capitalistas não se deve apenas, no âmbito ideológico, ao liberalismo e ao consequente abandono das tentativas de preservar o pleno emprego mediante políticas keynesianas; mas também principalmente às transformações econômicas ocasionadas pela Terceira Revolução Industrial e pela crescente globalização das atividades econômicas.

Nestes momentos de instabilidade econômica, várias pessoas que estão desempregados se tornam empreendedores, criam o próprio negócio porque não tem alternativa.

O objetivo deste artigo é comprovar que nos momentos de instabilidade econômica aumenta-se o número de empreendedores através de dados de pesquisas de instituições reconhecidas utilizando fontes de evidencias quantitativas. 


\section{O empreendedorismo}

O empreendedorismo é um marco na estrada para o progresso econômico, e faz uma contribuição enorme à qualidade e às esperanças futuras de um setor, de uma economia ou mesmo de um país. O empreendedorismo é tão importante nas pequenas e médias empresas (PMEs) e nos mercados locais como nas grandes empresas e nos mercados nacionais e internacionais, e é uma consideração tão importante para as empresas públicas como para as organizações privadas. O empreendedorismo contribui para encorajar a competição no ambiente atual que leva aos efeitos da globalização (Soriano \& Huarng, 2013).

Os estudos sobre empreendedorismo têm vindo a assumir uma grande importância. Isto deve-se ao fato: 1) o empreendedor ser responsável pelo crescimento económico e pelo desenvolvimento social; 2) por meio da inovação, dinamizar a economia; 3) o conceito de empreendedorismo implicar a ideia de sustentabilidade e tratar não só de indivíduos, mas de comunidades, cidades, regiões, países; 4) o empreendedorismo é a melhor arma contra o desemprego (Dolabela, 1999).

De acordo com Davidsson, \& Honig, (2003), as definições contemporâneas de empreendedorismo ou delineamentos de pesquisa em empreendedorismo focalizam o surgimento como em Gartner, (1988) e Shane e Venkataraman, (2000).

Shane e Venkataraman (2000) enfatizam que o empreendedorismo consiste de dois processos relacionados, a descoberta de oportunidades empresariais e a exploração dessas oportunidades.

Shane e Venkataraman (2000) definem o empreendedorismo como o "exame acadêmico de como, por quem, e com que efeitos as oportunidades de criar bens e serviços futuros são descobertas, avaliadas e exploradas". A atividade de empreendedorismo, em termos gerais, é necessária ter um grupo de pessoas dispostas a assumir riscos, usando seus fundos para gerar novas empresas e negócios. Esta é a melhor maneira de alcançar um crescimento econômico sustentável (NISSAN et al., 2011).

1. A definição tem em conta o comportamento dos agentes económicos. Por esta razão, empreendedorismo não significa uma ocupação, mas uma atividade que considera as diferentes circunstâncias e aspectos de uma pessoa. 
2. Os empreendimentos devem considerar a incerteza e os obstáculos inerentes ao processo de criação de negócios.

3. Eles devem ter informações ou ideias sobre processos de produção eficientes, bem como novas formas organizacionais. Isso não significa que os empresários tiveram de frequentar cursos acadêmicos especiais sobre administração. Eles devem ter a ideia e eles podem pedir informações ou conselhos de especialistas para executar a ideia.

4. Os empresários também podem ser encontrados em grandes empresas. Neste caso, são denominados "empresários" ou "empresários corporativos" (Arendt e Brettel 2010).

Segundo Hisrich \& Peters (2002), o empreendedorismo se caracteriza por uma capacidade de identificar oportunidades e criar algo inovador sob condições de incerteza, assumindo os riscos aí envolvidos. Persistência e visão de futuro envolvem o processo de empreender que tem como resultantes uma nova maneira de realizar um trabalho - um novo produto, serviço ou atividade - ou a criação de um novo empreendimento.

O fator de empreendedorismo também inclui pessoas que pesquisam informações ou ideias sobre processos de produção eficientes, bem como novas formas organizacionais. Tendo em conta estas ideias, diferentes tipos de empreendimentos podem ser considerados (Nissan et al., 2011).

O primeiro é o inovador, seguindo a tese de Schumpeter (1911, 1950). Schumpeter considera que a atividade de empreendedorismo implica inovação na introdução de um novo produto, organização ou processo, gerando um processo de destruição. O inovador cria novas indústrias e, por esta razão, provoca mudanças estruturais relevantes na economia. O segundo é o empreendedor que tira proveito das oportunidades de lucro (Kirzner, 1973, 1999). Terceiro, o elemento de incerteza deve ser levado em conta (Knight, 1921). E o quarto empreendimento produtivo e nãoprodutivo também deve ser considerado (Baumol, 1990).

Existem, também, diversas tipologias de empreendedores propostas por autores de diversas áreas de conhecimentos, neste trabalho utilizamos as tipologias propostas por Minello \& Scherer (2012), que apresentaram no artigo "Mudança de comportamento de empreendedores: uma análise dos tipos de empreendedores antes, durante e depois do insucesso empresarial", três tipologias baseadas no 
comportamento dos empreendedores na perspectiva de Vesper (1980), de Miner (1996) e de Filion (1999) conforme o quadro 1.

Quadro 1 - Tipologia de Empreendedor

\begin{tabular}{|c|c|c|}
\hline Tipo de Empreendedor & Características Comportamentais & Autor \\
\hline Autônomo & $\begin{array}{l}\text { Executam seus serviços } \\
\text { pessoalmente, baseando-se em } \\
\text { habilidade técnica. }\end{array}$ & \multirow{11}{*}{ Vésper (1980) } \\
\hline Formador de Equipes & $\begin{array}{l}\text { Contratam outras pessoas e delegam } \\
\text { tarefas, formando equipes, } \\
\text { percebendo uma possível vantagem } \\
\text { na expansão do negócio. }\end{array}$ & \\
\hline Inovador Independente & $\begin{array}{l}\text { Criadores de novos produtos, que } \\
\text { criariam empresas para desenvolvê- } \\
\text { los. }\end{array}$ & \\
\hline Multiplicador de Padrão & $\begin{array}{l}\text { Reconhecem um negócio, passível } \\
\text { de ser multiplicado visando a obter } \\
\text { lucro. }\end{array}$ & \\
\hline $\begin{array}{l}\text { Explorador de Economia de } \\
\text { Escala }\end{array}$ & $\begin{array}{l}\text { Criam seus negócios baseados em } \\
\text { preços menores obtidos devido à } \\
\text { economia de escala, localização em } \\
\text { áreas mais baratas e/ou com } \\
\text { impostos menores. }\end{array}$ & \\
\hline Agregador de Capital & $\begin{array}{l}\text { Captam recursos de diversas fontes } \\
\text { para bancar a operação de bancos, } \\
\text { seguradoras entre outras. }\end{array}$ & \\
\hline Aquisidor & $\begin{array}{l}\text { Optam por adquirir negócios que já } \\
\text { estão em processo de operação. }\end{array}$ & \\
\hline Especialista de Compra e Venda & $\begin{array}{l}\text { Compram empresas em dificuldades, } \\
\text { as recuperam e depois as vendem } \\
\text { por um preço maior. }\end{array}$ & \\
\hline Formador de Conglomerados & $\begin{array}{l}\text { Trabalham para obter controle } \\
\text { acionário de uma empresa para, a } \\
\text { partir desta, adquirir o controle de } \\
\text { outras empresas. }\end{array}$ & \\
\hline Especulador & $\begin{array}{l}\text { Dedicam-se a compra e venda de } \\
\text { commodities, como a área } \\
\text { imobiliária. }\end{array}$ & \\
\hline Manipulador de Valor Aparente & $\begin{array}{l}\text { Adquirem bens ou empresas baratas, } \\
\text { melhorando sua aparência ou índices } \\
\text { financeiros para revendê-los com }\end{array}$ & \\
\hline
\end{tabular}




\begin{tabular}{|c|c|c|}
\hline & elevação no preço. & \\
\hline Empreendedor Pessoal & $\begin{array}{l}\text { Procura ser bom em tudo o que faz, } \\
\text { possui iniciativa e comprometimento } \\
\text { com a organização, procura trabalhar } \\
\text { baseado no planejamento de } \\
\text { objetivos pessoais. }\end{array}$ & \multirow{4}{*}{ Miner (1996) } \\
\hline Especialista Gerador de Ideia & $\begin{array}{l}\text { Busca a inovação, procura atingir as } \\
\text { estratégias da empresa através de } \\
\text { novos produtos, novos nichos e } \\
\text { novos processos. Possui um bom } \\
\text { grau de inteligência, desejo por } \\
\text { ideias e tenta não correr risco. }\end{array}$ & \\
\hline Empático Supervendedor & $\begin{array}{l}\text { Acredita que a via adequada para o } \\
\text { sucesso empresarial é a força das } \\
\text { vendas, leva em consideração os } \\
\text { processos sociais, o bom } \\
\text { relacionamento com os indivíduos, } \\
\text { procura compreendê-los }\end{array}$ & \\
\hline Verdadeiro Gestor & $\begin{array}{l}\text { É aquele que procura se adaptar } \\
\text { para gerir um cargo de alta chefia, } \\
\text { tem o desejo de poder, relaciona-se } \\
\text { de maneira satisfatória com as } \\
\text { autoridades, busca a competição } \\
\text { empresarial, além de possuir uma } \\
\text { boa capacidade decisória. }\end{array}$ & \\
\hline Convertido & $\begin{array}{l}\text { Procura alguma coisa com que se } \\
\text { realize, quando encontra o que } \\
\text { buscava, sua vida gira em torno } \\
\text { dessa descoberta. Prefere ver a si } \\
\text { mesmo como uma pessoa } \\
\text { particularmente superior, ao invés de } \\
\text { ver os resultados, gostam de estar no } \\
\text { controle, por isso têm dificuldade de } \\
\text { delegar até que a outra pessoa prove } \\
\text { merecer confiança. }\end{array}$ & \multirow[t]{2}{*}{ Filion (1999) } \\
\hline Hobbysta & $\begin{array}{l}\text { Dedica toda a sua energia e o tempo } \\
\text { livre aos negócios. Frequentemente } \\
\text { possui outro emprego oficial, mas só } \\
\text { o mantêm como um apoio financeiro } \\
\text { para seu negócio. O negócio é seu } \\
\text { hobby. É nele que vê a possibilidade } \\
\text { de auto realização, assim investe } \\
\text { todos os recursos para desenvolvê- }\end{array}$ & \\
\hline
\end{tabular}




\begin{tabular}{|c|c|}
\hline & lo. \\
\hline Jogador & $\begin{array}{l}\text { Percebe o esporte e o lazer como } \\
\text { elemento vital em sua vida. } \\
\text { Considera a empresa um suporte } \\
\text { financeiro, um meio de ganhar o } \\
\text { suficiente para fazer o que realmente } \\
\text { quer. Opta por campos de atuação } \\
\text { sazonais. Não está de maneira } \\
\text { absoluta comprometido } \\
\text { emocionalmente com o negócio. }\end{array}$ \\
\hline Lenhador & $\begin{array}{l}\text { Caracteriza-se por gostar de fazer as } \\
\text { coisas, sente-se como se estivesse } \\
\text { perdendo tempo quando têm de falar } \\
\text { com pessoas, enquanto o } \\
\text { empregador prefere as pessoas que } \\
\text { trabalham durante muitas horas } \\
\text { como ele mesmo, sendo que a } \\
\text { cultura organizacional do seu } \\
\text { empreendimento está voltada para a } \\
\text { produção. }\end{array}$ \\
\hline Missionário & $\begin{array}{l}\text { Conhece muito bem o produto e o } \\
\text { mercado. Leva em consideração a } \\
\text { evolução e o aprendizado dos } \\
\text { indivíduos, compreende o negócio } \\
\text { como um sistema social, acredita que } \\
\text { os resultados dependem do trabalho } \\
\text { em equipe. Delega ao máximo, } \\
\text { participa de atividades em força- } \\
\text { tarefa, onde possam escutar discutir } \\
\text { e trocar experiências. }\end{array}$ \\
\hline Sedutor & $\begin{array}{l}\text { Entrega-se de maneira completa e } \\
\text { emocional aos negócios, mas seu } \\
\text { entusiasmo nunca dura muito. Cria } \\
\text { negócios e logo os vende, gosta que } \\
\text { as coisas aconteçam rapidamente. } \\
\text { Procura onde e como ter lucros com } \\
\text { o menor esforço possível. }\end{array}$ \\
\hline
\end{tabular}

Fonte: Vesper (1980), de Miner (1996) e de Filion (1999) 


\section{Metodologia}

As revisões da literatura apresentam-se como uma atividade importante para identificar, conhecer e acompanhar o desenvolvimento da pesquisa em determinada área do conhecimento (MIGUEL et al., 2007). Neste trabalho, foram pesquisados os tópicos empreendedorismo e as tipologias de empreendedores, conforme contextualizado na revisão de literatura.

A abordagem quantitativa apresenta uma realidade que pode ser quantificada ou mensurada e envolve itens da realidade da pesquisa. É possível trabalhar com os dados com tratamento estatístico específico, buscando a compreensão da realidade (Da Costa e da Costa, 2001).

Este estudo trata-se de uma pesquisa exploratória, baseada em dados secundários, com análise quantitativa de dados e amparada na literatura científica. Para Gil (2002), a pesquisa exploratória tem como objetivo proporcionar maior familiaridade com o problema, com vistas a torná-lo mais explícito. Zikmund (2002) considera que estudos exploratórios são conduzidos para clarificar problemas ambíguos, a pesquisa é necessária para entender melhor as dimensões dos problemas.

As fontes de evidências utilizadas foram:

I) Projeto GEM tem como objetivo compreender o papel do empreendedorismo no desenvolvimento econômico e social dos países. A pesquisa é parte do projeto Global Entrepreneurship Monitor, iniciado em 1999 por meio de uma parceria entre a London Business School e o Babson College, abrangendo no primeiro ano 10 países. Desde então, quase 100 países se associaram ao projeto, que constitui o maior estudo em andamento sobre o empreendedorismo no mundo. Em 2015, foram incluídos 60 países, cobrindo $70 \%$ da população global e 83\% do PIB mundial (GEM, 2015).

II) O Cadastro Geral de Empregados e Desempregados (CAGED) foi criado como registro permanente de admissões e dispensa de empregados, sob o regime da Consolidação das Leis do Trabalho (CLT). É utilizado pelo Programa de Seguro-Desemprego, para conferir os dados referentes aos vínculos trabalhistas, além de outros programas sociais. Este Cadastro serve, ainda, como base para a elaboração de estudos, pesquisas, projetos e programas 
ligados ao mercado de trabalho, ao mesmo tempo em que subsidia a tomada de decisões para ações governamentais (CAGED, 2017).

\section{Resultados e Analises}

\subsection{Panorama da instabilidade econômica no Brasil}

Utilizamos os seguintes indicadores econômicos para determinar o período de instabilidade e mostrar os baixos índices destes indicadores:

A) Saldo de empregados - O saldo refere-se ao total de admissões e dispensa de empregados, sob o regime da Consolidação das Leis do Trabalho - CLT. Os dados são do Ministério do Trabalho e Emprego, Cadastro Geral de Empregados e Desempregados (MTE/CAGED).

O gráfico 1 apresenta o saldo de empregados entre 2001 e 2016, observa-se que a partir do final de 2014 (2014.12), o saldo de empregados passa a ser negativo e permanece até o fim do período medido. $O$ saldo ser negativo indica que houve mais desempregados do que empregados neste período, indicando uma instabilidade em termos de contratações.

Gráfico 1 - Saldo de empregados

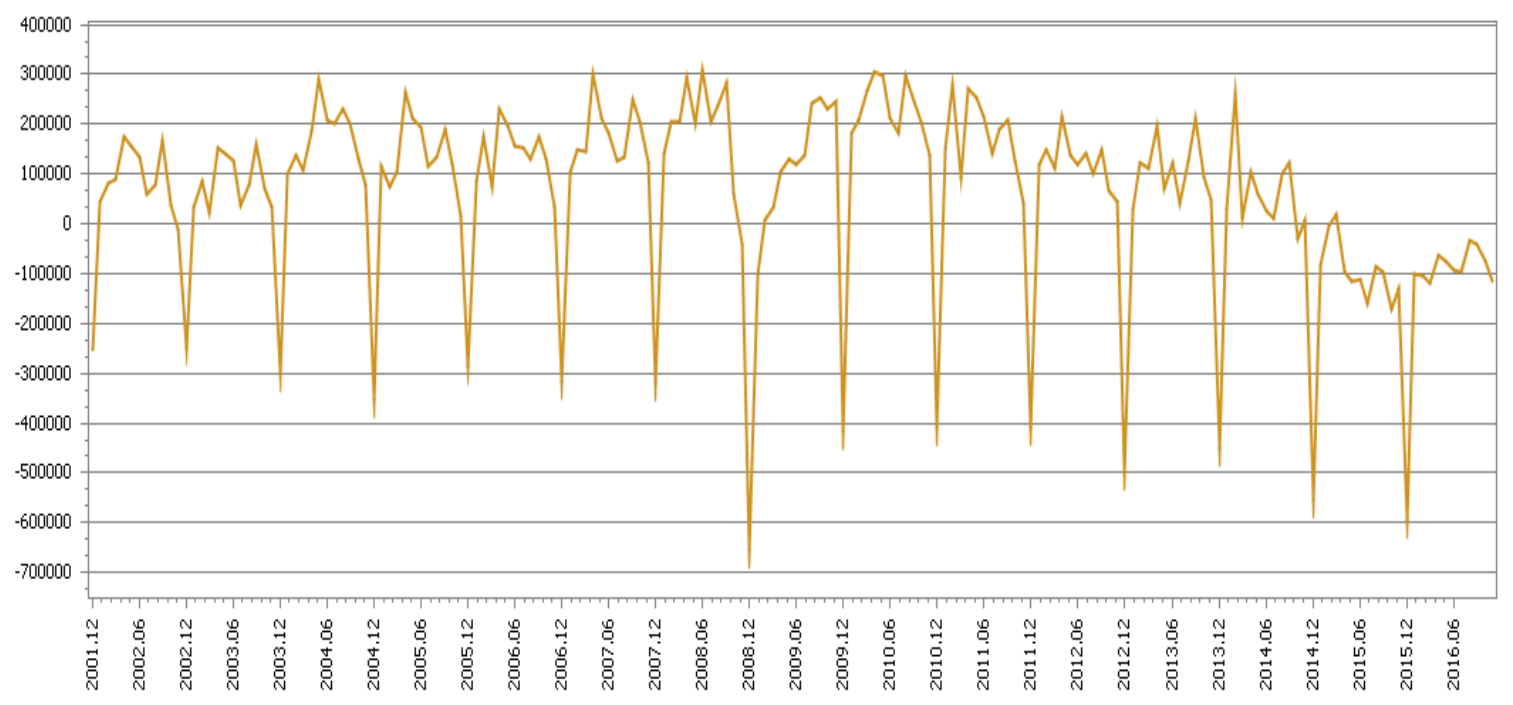

Fonte: ipeadata (www.ipeadata.gov.br) 
B) Produto interno bruto (PIB) real - Produto Interno Bruto (PIB) real a preços de mercado. Variação percentual em relação ao mesmo período do ano anterior. Dados do Instituto Brasileiro de Geografia e Estatística, Sistema de Contas Nacionais Referência 2010.

O gráfico 2 mostra a evolução do Produto interno bruto (PIB) real entre 1997 e 2016, nota-se que a partir do final de 2014 (2014.T3) o índice cai para valores negativos e permanece até final de 2016. Estes resultados mostram uma dificuldade em retomar o crescimento econômico, caracterizando um período de instabilidade.

Gráfico 2 - Produto interno bruto (PIB) real

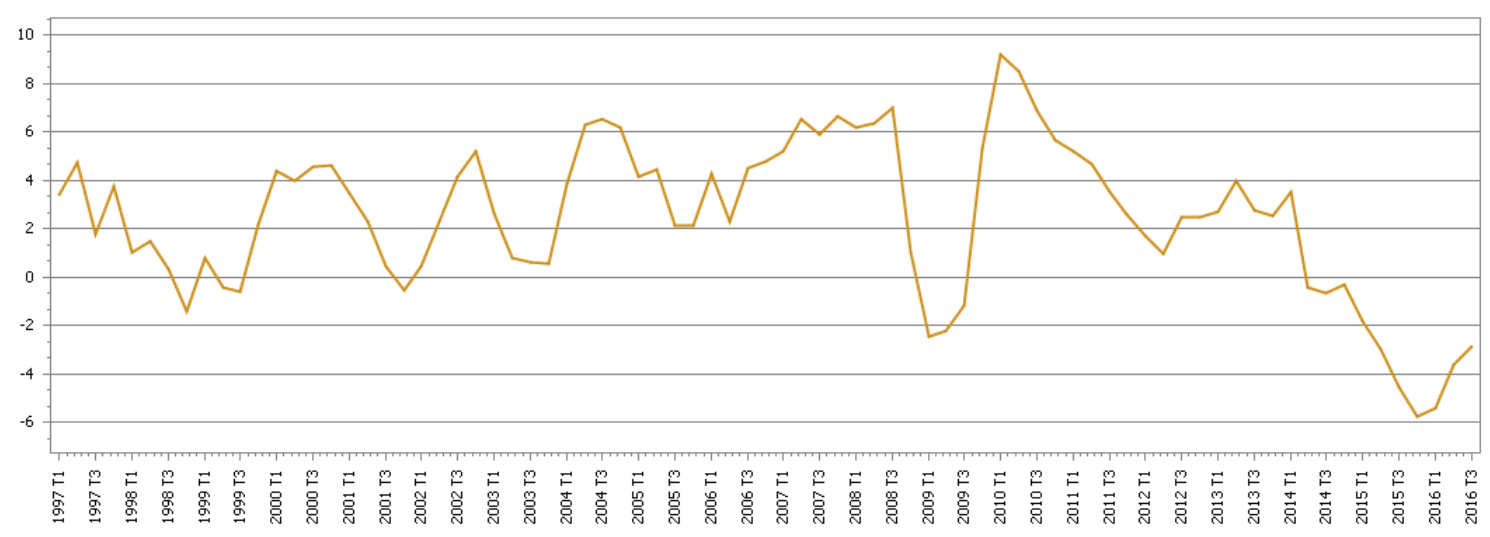

Fonte: ipeadata (www.ipeadata.gov.br)

O período de instabilidade apresentado nos dois indicadores analisados concentra-se no final de 2014 e final de 2016.

\subsection{Panorama do Empreendedorismo no Brasil}

Segundo GEM (2015), em 2015, a taxa total de empreendedorismo para o Brasil (TTE) foi de 39,3\%. Estima-se, portanto, que em 2015, 52 milhões de brasileiros com idade entre 18 e 64 anos estavam envolvidos na criação ou manutenção de algum negócio, na condição de empreendedor em estágio inicial ou estabelecido. Quando comparada à TTE de 2014 (34,4\%), observa-se que essa taxa sofreu um aumento significativo, intensificando a trajetória de crescimento observada desde 2011, gráfico 03. 
Gráfico 03 - Evolução das taxas ${ }^{1}$ de empreendedorismo segundo estágio do empreendimento TEA, TEE, TTE - Brasil - 2002:2015

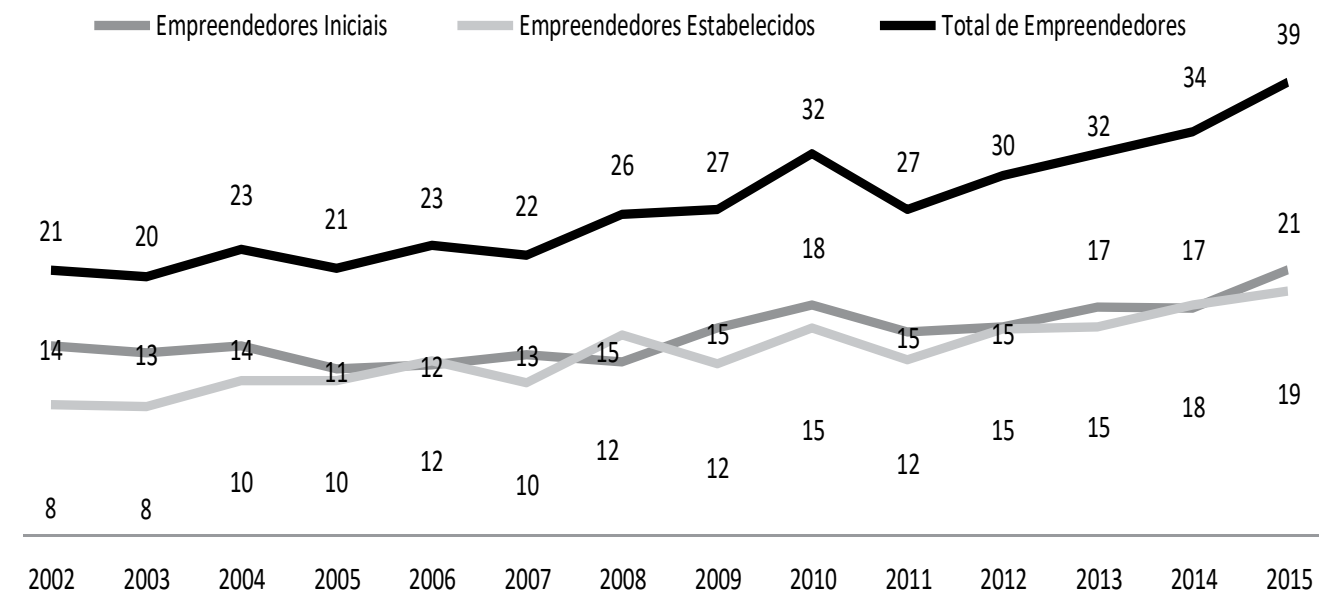

1 Percentual da população de 18 a 64 anos.

Fonte: GEM (2015)

Outros indicadores da pesquisa do GEM (2015) analisados foram:

Capacidades Percebidas - Percentagem de pessoas entre 18 e 64 anos que acreditam possuir as habilidades e conhecimentos necessários para iniciar um negócio

Taxa de receio de insucesso - Percentagem de 18-64 população percebendo boas oportunidades para iniciar um negócio que indicam que o medo do fracasso iria impedi-los de criação de um negócio

Atividade Empreendedor Inicial (TEA) - Percentagem de 18-64 população que são ou um empreendedor nascente ou proprietário-gerente de um novo negócio

Propriedade empresarial estabelecida - Percentagem de pessoas entre 18 e 64 anos que atualmente são dono-gerente de uma empresa estabelecida, isto é, possuir e administrar uma empresa em funcionamento que pagou salários, salários ou quaisquer outros pagamentos aos proprietários por mais de 42 meses.

Estes indicadores caracterizam a quantidade de pessoas que possuem estas caracteristicas empreendedoras. O grafico 4 apresenta a evolução dos indicadores de 2001 a 2015, observa-se que no periodo de 2014 a 2015, ha um crescimento em todos os indicadores. 
Gráfico 04 - Evolução das $\operatorname{taxas}^{1}$ de Capacidades Percebidas, receio de insucesso, TEA e propriedade empresarial estabelecida - Brasil - 2001:2015

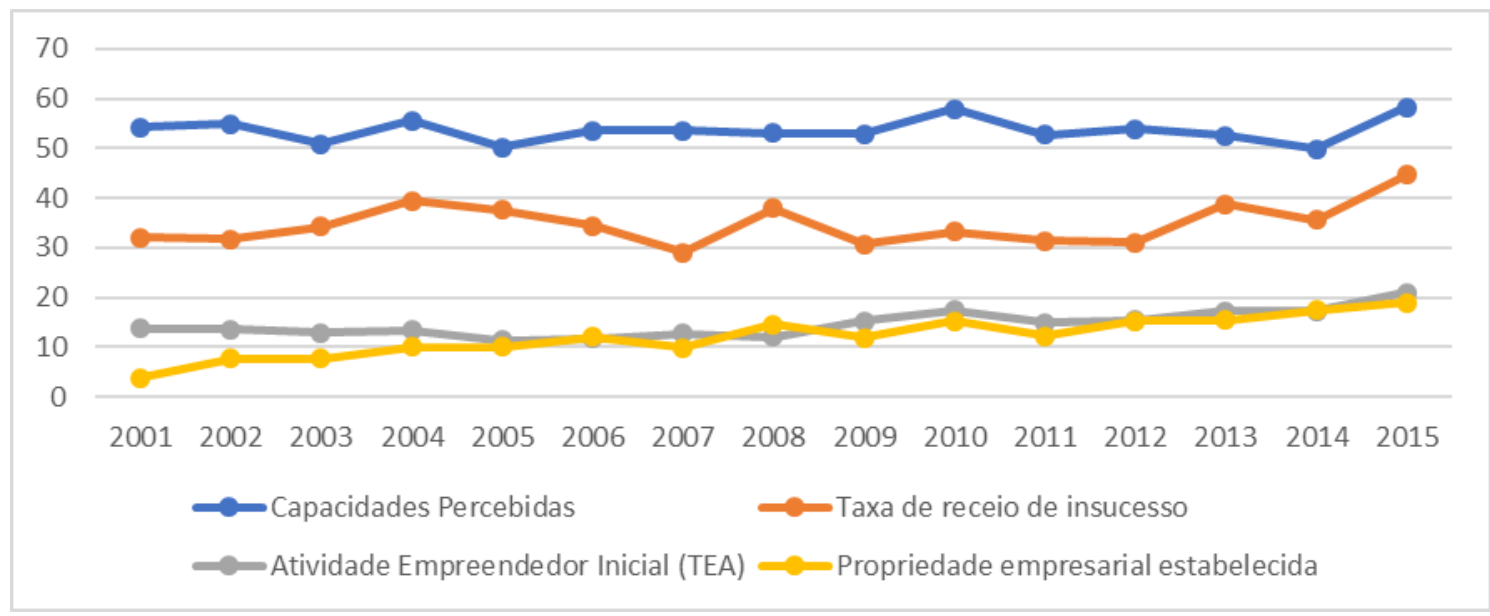

1 Percentual da população de 18 a 64 anos.

Fonte: GEM (2015)

\subsection{Consolidando os dois panoramas}

Os indicadores de instabilidade econômica comprovaram que o período de crise se inicia no final de 2014 e avança por 2015 e 2016, mas os indicadores de empreendedorismo no Brasil finalizam o período em 2015. Sendo assim, considerouse o período para análise dos panoramas o ano de 2015.

Enquanto no período de crise em 2015, os indicadores econômicos apresentaram valores negativos caracterizando a instabilidade econômica, os indicadores de empreendedorismo mostraram índices positivos comprovando um crescimento nos empreendedores brasileiros. 


\section{Conclusões Finais}

O empreendedorismo se faz mais presente nas épocas de crises econômicas, como podemos comprovar no aumento deste tipo de indicadores (Gráficos 3 e 4). Em alguns casos, devido ao desemprego, os trabalhadores que ficam desempregados procuram uma forma de sobreviver através da abertura de um empreendimento.

Enquanto os indicadores econômicos apresentaram índices negativos devido a uma crise econômica, os indicadores de empreendedorismo mostraram uma reação inversa com índices positivos, caracterizando um aumento nos empreendimentos.

Com as análises destes dois panoramas, alcançamos o objetivo de comprovar que nos momentos de instabilidade econômica aumenta-se o número de empreendedores através de dados de pesquisas de instituições reconhecidas utilizando fontes de evidencias quantitativas. 


\section{Referências Bibliográficas}

ARENDT, S.; BRETTEL, M. UNDERSTANDING THE INFLUENCE OF CORPORATE SOCIAL RESPONSIBILITY ON CORPORATE IDENTITY, IMAGE, AND FIRM PERFORMANCE". Management Decision, v. 48, n. 10, p. 1469-1492, 2010

Baumol, W.J. "Entrepreneurship: productive, unproductive and destructive", Journal of Political Economy, Vol. 98 No. 5, pp. 893-921. (1990)

CAGED. Cadastro Geral de Empregados e Desempregados (CAGED). Disponível em. http://trabalho.gov.br/trabalhador-caged/sobre-o-caged Acesso em 20/01/2017.

Da Costa, M. A. F; da Costa, M. de F. B. 2009. Metodologia da pesquisa: conceitos e técnicas. Interciência.

Dolabela, Fernando Celso (1999). O segredo de Luísa. São Paulo: Cultura Editores Associados

FILION, L. J. Empreendedorismo: empreendedores e proprietários-gerentes de pequenos negócios. Revista de Administração, v.34, n.2, p. 05-28, abril/junho. São Paulo, 1999.

Gartner, W.B., 1988. Who is an Entrepreneur is the wrong question. Am. Small Bus. J. 12, 11-31 (Spring).

GEM, Global Entrepreneurship Monitor. Empreendedorismo no Brasil: Relatório Executivo. Curitiba: Sebrae. 2015.

Gil, A. C. 2002. Como elaborar projetos de pesquisa. São Paulo, v. 5, p. 61

Hisrich, R. D., \& Peters, M. P. Entrepreneurship (5nd ed.). Boston: Irwin/McGraw Hill. (2002)

IBGE. Pesquisa Nacional por Amostra de Domicílios Contínua 2ํㅡㄹ trimestre de 2016. Disponivel em: ftp://ftp.ibge.gov.br/Trabalho e Rendimento/Pesquisa Nacional por Amostra de Do micilios continua/Trimestral/Fasciculos Indicadores IBGE/pnadc 201602 trimestre C aderno.pdf. Acessado em 17/09/2016. 
Kirzner, I.M., Competition \& Entrepreneurship, University of Chicago Press, Chicago, IL. (1973)

Knight, Frank H. Risk, Uncertainty, and Profit. Boston: Houghton Mifflin, 1921

MIGUEL, Paulo Augusto Cauchick et al. Estudo de caso na engenharia de produção: estruturação e recomendações para sua condução. Revista Produção, v. 17, n. 1, p. 216-229, 2007.

Minello, I. F., \& Scherer, L. A. (2012). Mudança de comportamento de empreendedores: uma análise dos tipos de empreendedores antes, durante e depois do insucesso empresarial. Revista Pensamento Contemporâneo em Administração, 6(4), 144-165.

MINER, J. B. Evidence for the Existence of a Set of Personality Types, Defined by Psychological Tests, that Predict Entrepreneurial Success. In: Frontiers of Entrepreneur Research, 1996 Edition, Babson College.

Nissan, E., Galindo, MA e Mendez, MT, "RELAÇÃO ENTRE ORGANIZAÇÕES, INSTITUIÇÕES, EMPREENDEDORISMO E PROCESSO DE CRESCIMENTO ECONÔMICO", Jornal Internacional Empreendedorismo e Gestão Vol. 7 No. 3, pp. 311-24. (2011)

Schumpeter, J.A. Capitalism, Socialism and Democracy, Harper \& Brother Publishers, New York, NY. (1950),

Schumpeter, J.A. The Theory of Economic Development, Oxford University Press, New York, NY. (1911),

Shane, S., Venkataraman, S., The promise of entrepreneurship as a field of research. Academy of Management Review 25, 217-226. 2000.

Singer, P. (2008). Globalização e desemprego: diagnóstico e alternativas. Petrópolis: Vozes. 
Soriano, Domingo Ribeiro. Huarng,, Kun-Huang. INNOVATION AND ENTREPRENEURSHIP IN KNOWLEDGE INDUSTRIES, Journal of Business Research, Volume 66, Issue 10, October 2013

VESPER, K. H. Perspectives on Entrepreneurship. In: New Venture Strategies. Chapter 1, p. 1-26. Englewood Cliffs: Prentice Hall, 1980.

Zikmund, W.G. 2000. "BUSINESS RESEARCH METHODS". 6th edition. The Dryden Press. Fort Worth 